\title{
Prevalence and predictors of ocular complications among children undergoing nephrotic syndrome treatment in a resource-limited setting
}

Faith Nakubulwa ${ }^{1 *}$, Rebecca Claire Lusobya ${ }^{1}$, Anthony Batte ${ }^{2}$, Bashir Ssuna ${ }^{3}$, Damalie Nakanjako ${ }^{4}$, Lydia Nakiyingi ${ }^{4}$, Caroline Nalukenge ${ }^{1}$, Francis Onen Sebabi ${ }^{1}$, Ben Mulinde ${ }^{1}$ and Juliet Otiti-Sengeri ${ }^{1}$

\begin{abstract}
Background: Nephrotic syndrome is the most common glomerulopathy among children aged 2-18 years and high dose corticosteroids are the backbone of its management. Potentially blinding ocular complications often result from nephrotic syndrome and/or its treatment. We conducted a study to determine the prevalence and predictors of ocular complications among children undergoing nephrotic syndrome treatment at Mulago National Referral Hospital.

Methods: This was a cross-sectional study conducted for three [3] months at the pediatric renal unit of Mulago National Referral Hospital (MNRH). Data from a consecutive sample of 100 children was collected using a semistructured questionnaire, entered into Epi-data 4.4.2 and exported to STATA 14 for analysis at univariate, bivariate and multivariate levels. A robust Poisson regression model was used to identify predictors of ocular complications.

Results: Out of 100 patients examined, 80(80\%) had ocular complications. The median age was 10 (IQR: 7-12) and 52 (52\%) were girls. The most frequent complications were hypertrichosis and refractive errors in $71 \%(95 \% \mathrm{Cl} 61.1-$ $79.6)$ and $56 \%(95 \% \mathrm{Cl} 45.7-65.9)$ of the patients respectively. Age above 10 years was the predictor for ocular complications with a $\mathrm{RR}=1.37(95 \% \mathrm{Cl}: 1.14-1.64) p=0.001$.
\end{abstract}

Conclusions: We found a high prevalence of ocular complications among children with nephrotic syndrome in this tertiary hospital. The predictor of ocular complications was age greater than 10 years. We recommend that all children with nephrotic syndrome undergo a baseline ocular examination prior to commencement of treatment and be reviewed periodically by an ophthalmologist.

Keywords: Nephrotic syndrome, Corticosteroids, Ocular complications, Resource limited setting

\footnotetext{
* Correspondence: faithdallan@gmail.com

'Department of Ophthalmology, School of Medicine, Makerere University

College of Health Sciences, Kampala, Uganda

Full list of author information is available at the end of the article
}

(c) The Author(s). 2021 Open Access This article is licensed under a Creative Commons Attribution 4.0 International License, which permits use, sharing, adaptation, distribution and reproduction in any medium or format, as long as you give appropriate credit to the original author(s) and the source, provide a link to the Creative Commons licence, and indicate if changes were made. The images or other third party material in this article are included in the article's Creative Commons licence, unless indicated otherwise in a credit line to the material. If material is not included in the article's Creative Commons licence and your intended use is not permitted by statutory regulation or exceeds the permitted use, you will need to obtain permission directly from the copyright holder. To view a copy of this licence, visit http://creativecommons.org/licenses/by/4.0/. The Creative Commons Public Domain Dedication waiver (http://creativecommons.org/publicdomain/zero/1.0/) applies to the data made available in this article, unless otherwise stated in a credit line to the data. 


\section{Background}

Nephrotic syndrome (NS) is the most common glomerulopathy in children aged 2-18 years. It puts the patient at a risk of life threatening infections and thromboembolic events if left untreated [1]. Several reports from different settings have indicated variations in the annual incidence of nephrotic syndrome ranging from 2 to 16.7 per 100 , 000 cases worldwide, with 5.6 per million children in Tropical Africa [2]. In Uganda, the estimated incidence of nephrotic syndrome was at 160 per million population in 2017 [3] . Despite the good therapeutic effects, the use of systemic corticosteroids is associated with multisystem side effects and ophthalmic complications [4]. This has been observed in children who start corticosteroid treatment at a young age, longer duration of therapy [5-7] and a prednisolone dose of 10-15 mg per day for a year has been associated with visually significant cataract [8].

In Mulago National Referral Hospital; Uganda's national referral hospital, there is currently no baseline ophthalmology screening or follow-up being done for children initiated on corticosteroid treatment for NS and yet over 100 have been managed for the condition according to Mulago Hospital Nephrology department 2018/2019 records. This subjects a large proportion of children to ocular complications, consequently leading to visual disturbances that negatively impact on the quality of life of these children, their performance in school, emotional and social wellbeing. Visual disturbances also translate into a significant socioeconomic burden on family and society due to increased resources needed to raise a visually impaired child [9]. Early detection and prompt management of the side effects can prevent visual deprivation and eventual amblyopia due to cataracts as well as permanent blindness in cases of optic nerve damage in steroid induced glaucoma [10].

It is necessary that patients who are on long term treatment with corticosteroids including those with NS undergo timely examination by an ophthalmologist [1, 11 ] and prompt referral is instituted for patients at risk of developing steroid-induced glaucoma. Currently, there is a paucity of studies on the occurrence and predictors of ocular complications among children with NS receiving corticosteroids. There are no documented national or hospital guidelines on Ophthalmological screening, management and follow-up of patients with nephrotic syndrome to assess for ocular complications related to the disease and/or its treatment in this resource-limited setting. This study on the prevalence and predictors for ocular complications among children undergoing NS treatment was conducted at a national referral hospital in Uganda, to generate information which may potentially be used by clinicians and policy makers to inform policy and guide development of management and follow-up guidelines for children with NS to reduce ocular complications which subsequently result into visual disturbances. The objectives of this study were to determine the prevalence and predictors of ocular complications among children undergoing nephrotic syndrome treatment at mulago national referral hospital.

\section{Methods}

\section{Study design and setting}

This was a hospital-based, cross-sectional study conducted in Kampala district, Uganda with participants from the pediatric renal unit of Mulago National Referral Hospital (MNRH) between January 2020 and March 2020. The department has both in and outpatient nephrology units which receive patients with nephrotic syndrome all year round who are routinely started on oral corticosteroids as first line of treatment. There is no routine ophthalmology check for these children unless symptomatic.

\section{Study population}

We included all children who had been consented and/ or assented with nephrotic syndrome at MNRH in the pediatric renal unit who were aged 1 to 18 years with documented diagnosis of nephrotic syndrome during the study period. We excluded all children with ocular congenital anomalies and those who were too ill to undergo full ophthalmic exam.

\section{Data collection procedures and instruments}

The study doctor collected data on socio-demographic characteristics, clinical characteristics and treatment characteristics of patients. We used an intervieweradministered questionnaire to collect data on the participants. We then reviewed the file of the participant from the time he or she was admitted up to the current date and recorded the details of the treatment, remissions and relapses. Study-targeted history was collected from the patient followed by physical and ocular examination which was recorded. During ocular examination, visual acuity was measured using an illuminated Snellen chart at $6 \mathrm{~m}$ for school going children, Lea test; the gratings for 12-24 months and Cardiff test for 18-60 months. Each eye was occluded in turn and the best visual acuity (VA) assessed. Those found with VA worse than 6/6 had their vision with pinhole assessed and any changes recorded. Visual fields were also tested by the confrontational method. Eye movements were tested in all gazes seeking any paresis or paralysis of extra ocular muscles. Portable slit lamp biomicroscopy was done on all the study participants and findings in the anterior segment recorded. Tonomety was done using a handheld Perkin's applanation tonometer after the instillation of anesthetic 
drops (amethocaine) and staining the tear film with fluorescein. The pupils were dilated with cyclopentolate after which a detailed lens examination was done. Wet retinoscopy was done to categorize the refractive errors. Fundus examination was done using an indirect ophthalmoscope and photos taken using Volk iNView Fundus camera and images reviewed by the supervising Ophthalmologist.

Abnormalities found during the ocular examination were documented and children referred to the ophthalmology department for further care.

\section{Data management and analysis}

To determine the prevalence of complications we used a finite sample, at 95\% confidence interval and considered a $50 \%$ proportion to have complications. While for predictors, we used the Fleiss formula for comparing two proportions and participants were enrolled consecutively.

The collected data was entered into Epidata 4.2 using double entry method, cleaned and exported as a STATA database to STATA 15.1/MP for analysis. The prevalence of ocular complications was determined as a proportion of those who had complications divided by the total number of participants enrolled. The predictors of complications were determined by a robust modified Poisson regression analysis to estimate the risk ratios with their 95\% confidence intervals and their $P$-values. At bivariate analysis; clinical and demographic predictors which had a $p$ value $<0.2$ were included at multivariate level at which only those with a $p$ value $<0.05$ were considered significant.

\section{Results}

\section{Participant characteristics}

Of the 100 study participants enrolled, 52(52\%) were female; the mean age was 10 years (SD 4). Majority of the patients (83\%) examined were between 7 and 12 years of age. Majority of the children were in primary school 70(70\%) (Table 1).

Sixteen children (16\%) had history of hypertension. One child out of 18 with confirmed HIV results was HIV positive (Table 1).

\section{Prevalence of ocular complications}

A total of $80 / 100,80 \%$ (95\% CI: 70.8-87.3) participants had ocular complications. Seventy-one (71\%) patients had hypertrichosis of the eye lashes, 56 (56\%) had refractive errors, $16(16 \%)$ had raised intraocular pressure (IOP) and 1 (1\%) had cataract (Table 2).

Myopic astigmatism was the most common refractive error with 32/103 (31\%) eyes. (Fig. 1). The IOP range in the patients with myopic astigmatism was $21-30 \mathrm{mmHg}$.
Predictors of ocular complications among children with nephrotic syndrome at Mulago hospital

At bivariate analysis, current age above 10 years $(R R=$ $1.80, p=0.012$ ), a diagnosis of steroid dependent nephrotic syndrome $(\mathrm{RR}=1.24, p=0.127)$, frequent relapses $(\mathrm{RR}=1.25, p<0.001)$, and a cumulative dose per square meter between 5000 and $10,000 \mathrm{mg} / \mathrm{m}^{2}(\mathrm{RR}=1.18, p=$ $0.101)$ were statistically significant $(p<0.2)$ and considered for further analysis at multivariate analysis.

At multivariate analysis, current age above 10 years $\mathrm{RR}=1.37(95 \% \mathrm{CI}: 1.14-1.64) \quad p=0.001$ was the significant predictor of ocular complications among children with nephrotic syndrome.

\section{Discussion}

The prevalence of ocular complications among children with nephrotic syndrome at MNRH was found to be $80 \%$. This was high and probably explained by the high proportion of hypertrichosis among the ocular complications which does not revert in many patients even when medication is stopped [12].

We found no previous studies that stated the prevalence of ocular complications among children with nephrotic syndrome. Majority of the children with NS attending MNRH had one or more ocular complication.

Systemic steroids gain access to the ocular tissues via the blood stream and if taken for a long duration as in NS treatment, their effects on apoptosis, stability of cell membranes, proteolysis and phagocytosis of extracellular matrix contribute to development of the various complications [13-16].

Hypertrichosis was the most frequent ocular complication in this study at $71(71 \%)$.Systemic steroids promote facial hypertrichosis through unknown mechanisms [17]. Hypertrichosis has not been reported by previous researchers among children with nephrotic syndrome, however, it was reported among 23 Dutch asthmatic children on inhaled corticosteroids as an adverse effect [12]. Differences occurred in individual susceptibility; occurrence and non-reversal of hypertrichosis and could have been the case for the patients we examined [12].

While Epiblepharon (46.6\%) was the most prevalent ocular abnormality among Japanese children with NS, it was not reported among our patients [7]. This was probably because Asians have a more anterior insertion of the levator aponeurosis making epiblepharon prevalent even in their general population [18].

Refractive errors were found in 56 children (56\%) and a total of 103 eyes; myopic astigmatism being the most frequent $32(29 \%)$. It has been postulated by various researchers that the fluctuating intraocular pressures (IOPs) cause stretching of the globe and transient increases in the axial length resulting in myopic astigmatism, however, no direct correlation has been found [16]. 
Table 1 Participant characteristics and predictors of ocular complications among children with nephrotic syndrome at Mulago hospital

\begin{tabular}{|c|c|c|c|c|c|c|c|c|}
\hline \multirow[t]{2}{*}{ Characteristic } & \multirow[t]{2}{*}{ Total } & \multirow[t]{2}{*}{ Proportion(\%) } & \multicolumn{2}{|c|}{ Ocular complications } & \multirow[t]{2}{*}{ Crude RR } & \multirow[t]{2}{*}{$P$-value } & \multirow{2}{*}{$\begin{array}{l}\text { Adjusted } \\
\text { RR(95\% Cl) }\end{array}$} & \multirow[t]{2}{*}{$P$-Value } \\
\hline & & & No $(n, \%)$ & Yes (n, \%) & & & & \\
\hline \multicolumn{9}{|l|}{ Current age in years } \\
\hline mean $\pm S D$ & $10 \pm 4$ & & & & & & & \\
\hline $1-5$ & 17 & 17 & $8(47.1)$ & $9(52.9)$ & 1 & & 1 & \\
\hline $6-10$ & 42 & 42 & $10(23.8)$ & $32(76.2)$ & 1.44 & 0.138 & $1.44(0.89,2.33)$ & \\
\hline$>10$ & 41 & 41 & $2(4.9)$ & $39(95.1)$ & 1.8 & 0.012 & $1.37(1.14,1.64)$ & $0.001^{*}$ \\
\hline \multicolumn{9}{|l|}{ Sex } \\
\hline Female & 52 & 52 & $13(25.0)$ & $39(75.0)$ & 1 & & & \\
\hline Male & 48 & 48 & $7(14.6)$ & $41(85.4)$ & 1.14 & 0.195 & & \\
\hline \multicolumn{9}{|l|}{ Residence } \\
\hline Rural & 34 & 34 & $6(17.7)$ & $28(82.3)$ & 1 & & & \\
\hline Semi-urban & 32 & 32 & $8(25.0)$ & $24(75.0)$ & 0.91 & 0.472 & & \\
\hline Urban & 34 & 34 & $6(17.7)$ & $28(82.3)$ & 1.01 & 0.999 & & \\
\hline \multicolumn{9}{|l|}{ Education } \\
\hline Pre-school & 21 & 21 & $9(42.9)$ & $12(57.1)$ & 1 & & & \\
\hline Primary & 79 & 79 & $11(13.9)$ & $68(86.1)$ & 1.51 & 0.003 & & \\
\hline \multicolumn{9}{|l|}{ Weight at diagnosis } \\
\hline$<20$ & 36 & 36 & $10(27.8)$ & $26(72.2)$ & 1 & & & \\
\hline $20-29$ & 34 & 34 & $7(20.6)$ & $27(79.4)$ & 1.1 & 0.485 & & \\
\hline$\geq 30$ & 30 & 30 & $3(10.0)$ & $27(90.0)$ & 1.25 & 0.068 & & \\
\hline \multicolumn{9}{|l|}{ HIV Status } \\
\hline Negative & 17 & 17 & $3(17.7)$ & $14(82.3)$ & 1 & & & \\
\hline Positive & 1 & 1 & 0 & $1(100)$ & 1.21 & 0.085 & & \\
\hline Unknown & 82 & 82 & $17(20.7)$ & $65(79.3)$ & 0.96 & 0.762 & & \\
\hline \multicolumn{9}{|l|}{ Current diagnosis } \\
\hline In remission & 24 & 24 & $6(25.0)$ & $18(75.0)$ & 1 & & & \\
\hline NS & 62 & 62 & $13(21.0)$ & $49(79.0)$ & 1.05 & 0.699 & & \\
\hline SDNS & 14 & 14 & $1(7.1)$ & $13(92.9)$ & 1.24 & 0.127 & & \\
\hline \multicolumn{9}{|l|}{ Hypertension } \\
\hline No & 84 & 84 & $18(21.4)$ & 66 (78.6) & 1 & & & \\
\hline Yes & 16 & 16 & $2(12.5)$ & $14(87.5)$ & 1.11 & 0.332 & & \\
\hline \multicolumn{9}{|l|}{ Medication } \\
\hline Combination & 19 & 19 & $3(15.8)$ & $16(84.2)$ & 1 & & & \\
\hline Only prednisolone & 81 & 81 & $17(21.0)$ & $64(79.0)$ & 0.94 & 0.58 & & \\
\hline \multicolumn{9}{|c|}{ Use of traditional eye medicine } \\
\hline No & 97 & 97 & 19 (19.6) & $78(80.4)$ & 1 & & & \\
\hline Yes & 3 & 3 & $1(33.3)$ & $2(66.7)$ & 0.83 & 0.65 & & \\
\hline \multicolumn{9}{|c|}{ Number of days on treatment } \\
\hline$<100$ & 20 & 20 & $6(30.0)$ & $14(70.0)$ & 1 & & & \\
\hline 100-199 & 22 & 22 & $5(22.7)$ & $17(77.3)$ & 1.1 & 0.598 & & \\
\hline$\geq 200$ & 58 & 58 & $9(15.5)$ & $49(84.5)$ & 1.21 & 0.233 & & \\
\hline \multicolumn{9}{|c|}{ Average daily dose of Prednisolone } \\
\hline$<15 \mathrm{mg}$ & 22 & 22 & $3(13.6)$ & $19(86.4)$ & 1 & & & \\
\hline $15-30 \mathrm{mg}$ & 58 & 58 & $14(24.1)$ & $44(75.9)$ & 0.88 & 0.252 & & \\
\hline
\end{tabular}


Table 1 Participant characteristics and predictors of ocular complications among children with nephrotic syndrome at Mulago hospital (Continued)

\begin{tabular}{|c|c|c|c|c|c|c|c|c|}
\hline \multirow[t]{2}{*}{ Characteristic } & \multirow[t]{2}{*}{ Total } & \multirow[t]{2}{*}{ Proportion(\%) } & \multicolumn{2}{|c|}{ Ocular complications } & \multirow[t]{2}{*}{ Crude RR } & \multirow[t]{2}{*}{$P$-value } & \multirow{2}{*}{$\begin{array}{l}\text { Adjusted } \\
\text { RR(95\% Cl) }\end{array}$} & \multirow[t]{2}{*}{$P$-Value } \\
\hline & & & No $(n, \%)$ & Yes (n, \%) & & & & \\
\hline$>30 \mathrm{mg}$ & 20 & 20 & $3(15.0)$ & $17(85.0)$ & 0.98 & 0.999 & & \\
\hline \multicolumn{9}{|c|}{ Cumulative dose per square meter } \\
\hline$<5000$ & 61 & 61 & $15(24.6)$ & $46(75.4)$ & 1 & & & \\
\hline $5000-10,000$ & 27 & 2 & $3(11.1)$ & $24(88.9)$ & 1.18 & 0.101 & & \\
\hline$>10,000$ & 12 & 12 & $2(16.7)$ & $10(83.3)$ & 1.11 & 0.503 & & \\
\hline \multicolumn{9}{|c|}{ Average daily dose of prednisolone per kg weight } \\
\hline$<1$ & 57 & 57 & $10(17.5)$ & $47(82.5)$ & 1 & & & \\
\hline $1-1.5$ & 30 & 30 & $6(20.0)$ & $24(80.0)$ & 0.97 & 0.784 & & \\
\hline$>1.5$ & 13 & 13 & $4(30.8)$ & $9(69.2)$ & 0.84 & 0.372 & & \\
\hline \multicolumn{9}{|l|}{ Number of relapses } \\
\hline Infrequent relapse & 99 & 99 & $20(20.2)$ & 79 (79.8) & 1 & & & \\
\hline Frequent relapse & 1 & 1 & 0 & $1(100)$ & 1.25 & $<0.001$ & & \\
\hline
\end{tabular}

Table 1 shows the characteristics and predictors of ocular complications among children with nephrotic syndrome at mulago national referral hospital SD Standard deviation, HIV Human Immunodeficiency Virus, kg Kilogram, NS Nephrotic syndrome, SDNS Steroid dependent nephrotic syndrome

${ }^{a}$ combination $=$ prednisolone + one or more of; cyclophosphamide, mycophenolate mofetil, methotrexate

* $P<0.2$ at bivariate

$P<0.005$ at multivariate.

In Kampala, the most prevalent refractive error among primary school children was found to be astigmatism at $52 \%$ followed by hyperopia which made our findings different from the general population [19]. Similarly, other studies also found myopic astigmatism as the commonest refractive error among children with nephrotic syndrome. A study by Gheissari et al. found prevalence of myopic astigmatism at $18(24 \%)$ [20], Ozaltin recorded myopic astigmatism as the only refractive error among the three children with nephrotic syndrome whom he examined [21] and Agrawal et al. in India found myopic astigmatism as the only refractive error at $5(5 \%)$ related to steroid therapy among children with nephrotic syndrome [11].
Elevated IOP was recorded in $16(16 \%)$ patients. This was comparable to results from similar studies. Gaur found elevated IOP in $10.97 \%$ of the children with Nephrotic syndrome he examined in India [22]. In Japan, $20 \%$ of children with nephrotic syndrome had elevated IOP [7]. Agrawal found elevated IOP in $2 \%$ of the children with NS that he examined [11]. Corticosteroids which are the mainstay of treatment for nephrotic syndrome cause an elevated IOP by increasing resistance of aqueous outflow at the level of the Trabecular meshwork [14].

This current study found PSC in 1(1\%) of the children with NS. This was lower than what other studies found elsewhere. In Japan, 33.3\% of the children with

Table 2 Types of ocular complications among children with nephrotic syndrome at Mulago National Referral Hospital

\begin{tabular}{llll}
\hline Complications & Frequency $(\mathbf{n})$ & Proportion (\%) & 95\%Confidence Interval \\
\hline Hypertrichosis & 71 & 71 & $61.1-79.6$ \\
Refractive Errors & 56 & 56 & $45.7-65.9$ \\
Allergic conjunctivitis & 37 & 37 & $27.6-47.2$ \\
Elevated IOP & 16 & 16 & $9.4-24.7$ \\
Bacterial conjunctivitis & 10 & 10 & $4.9-17.6$ \\
Blepharitis & 10 & 10 & $4.9-17.6$ \\
Hordeolums & 2 & 2 & $0.2-7.0$ \\
Corneal scar & 1 & 1 & $0.02-5.4$ \\
Cataract & 1 & 1 & $0.02-5.4$ \\
Optic disc pallor & 1 & 1 & $0.02-5.4$ \\
\hline
\end{tabular}

IOP Intraocular pressure 


\section{Refractive errors}

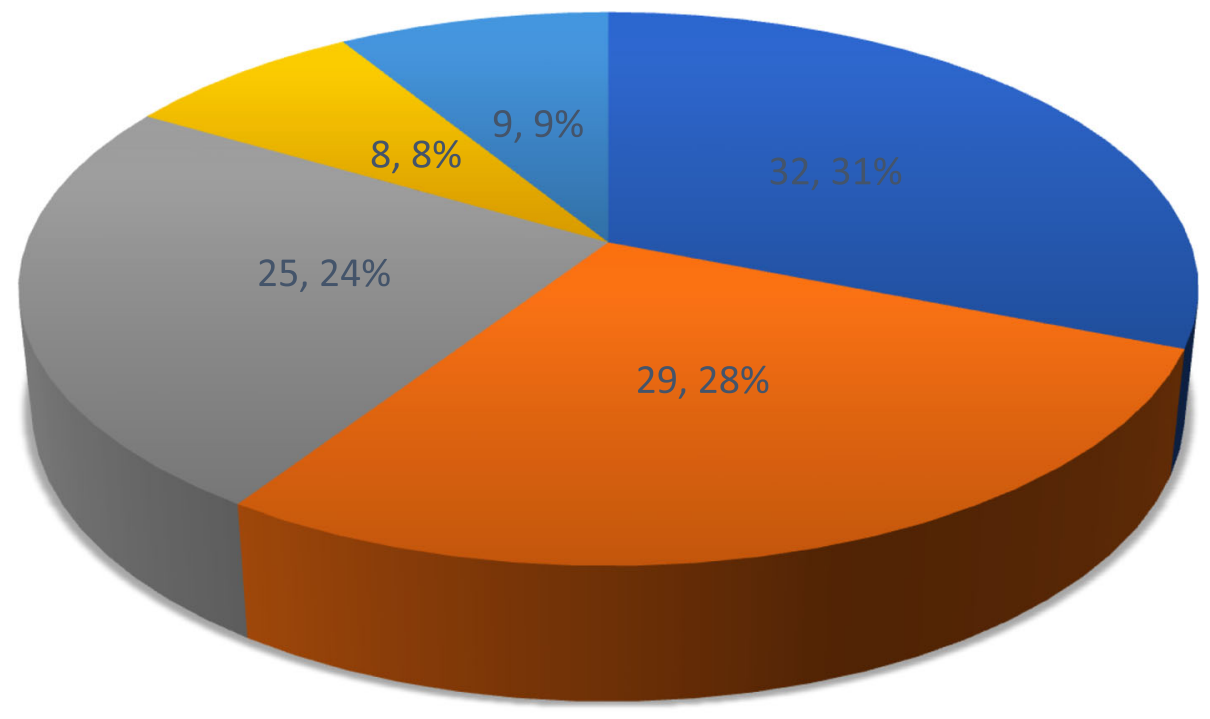

myopic astigmatism

hyperopia

astigmatism

myopia

hyperopic astigmatism

Fig. 1 Illustrates the various types of refractive errors among children undergoing nephrotic syndrome treatment; myopic astigmatism was the most common at 32(31\%) followed by hyperopia at 29(28\%) eyes

NS examined by Hayasaka had PSC while Gaur recorded $26.8 \%$ in India, Olonan et al. reported a similarly high occurrence of $13.6 \%$ in Manilla Philippines and Wong recorded $10.3 \%[5,23]$. The difference in the frequency of PSC among the patients with NS in MNRH from those examined elsewhere could not be explained further since this was the first study in an African population. Cotlier proposed that steroids gain entry into the fiber cells of the crystalline lens, react with specific amino acids causing alterations and protein aggregation leading to lens opacification [24].

In our study, children who were 10 years and above had almost twice risk of developing ocular complications than those between 1 and 5 years. This could be because older children had started treatment earlier and therefore had been exposed to the steroids longer than the younger children as reported by Kobayashi et al., 1974 and Brocklebank et al., 1982 [25, 26].

\section{Conclusions and recommendations}

We found a high prevalence of ocular complications among children undergoing nephrotic syndrome treatment in this tertiary hospital. The predictor of ocular complications was age greater than 10 years. We recommend that all children with nephrotic syndrome undergo a baseline ocular examination prior to commencement of treatment and be reviewed periodically by an ophthalmologist.

\section{Strengths and limitations of the study}

It was the first study of this kind in an African population. It is also the only study that has estimated the prevalence of ocular complications among children with nephrotic syndrome. Due to limitation of resources; retinal and choroidal thickening as well as axial length which could have added more meaning to the findings were not measured. Patients were not followed up post steroid therapy to measure residual myopic shift.

\section{Supplementary Information}

The online version contains supplementary material available at https://doi. org/10.1186/s12886-021-01817-6.

\section{Additional file 1}




\section{Abbreviations}

IOP: Intraocular Pressure; MNRH: Mulago National Referral Hospital; NS: Nephrotic syndrome; PSC: Posterior Subcapsular Cataract; SOMREC: School of Medicine Research Ethics Committee

\section{Acknowledgements}

We acknowledge the Uganda Cancer Institute for the funding and Vinayak S. Joshi for availing the Volk iNView fundus camera. We also acknowledge all the staff members of Eye Clinic and the Paediatrics renal unit of Mulago National Referral Hospital, particularly Grace Muwanga and Loyce Nassozi for the support and cooperation rendered to me in the execution of this research. The authors gratefully acknowledge the participants who accepted to be part of this study.

\section{Authors' contributions}

FN conceived the idea; FN, $A B$, JOS, RCL developed the idea; FN obtained the funding; FN, CN, BM, FOS collected the data; FN, BS, AB, LN, DN, JOS performed the analysis and interpretation; FN drafted the article. All authors contributed to reviewing and revising this manuscript and gave final approval of the version.

\section{Funding}

This research was funded by Uganda Cancer Institute-African Development Bank; Award number ADM/11/2018. The contents are solely the responsibility of the authors and do not represent the official views of the funding body.

\section{Availability of data and materials}

The datasets used and analyzed during this study are available from the corresponding author on reasonable request.

\section{Ethics approval and consent to participate}

The study was approved by the Makerere University and the School of Medicine Research and Ethics Committee (SOMREC) under study number; REC REF. Number 2019-151. The study included participants who were below the age of 18 years. Written consent was obtained from the parent or guardian on behalf of each participant. Assent was obtained from all participants who were 7 years and older.

\section{Consent for publication}

Not applicable.

\section{Competing interests}

The authors declared no conflict of interest.

\section{Author details}

${ }^{1}$ Department of Ophthalmology, School of Medicine, Makerere University College of Health Sciences, Kampala, Uganda. ${ }^{2}$ Child Health and Development Centre, Makerere University College of Health Sciences, Kampala, Uganda. ${ }^{3}$ Department of Epidemiology and Biostatistics, School of Medicine, Makerere University College of Health Sciences, Kampala, Uganda. ${ }^{4}$ Department of Medicine, School of Medicine, Makerere University College of Health Sciences, Kampala, Uganda.

Received: 4 September 2020 Accepted: 12 January 2021

Published online: 22 January 2021

\section{References}

1. Bagga A, Mantan M. Nephrotic syndrome in children. Indian J Med Res. 2005;122(1):13-28.

2. Olowu WA, Ademola A, Ajite AB, Saad YM. Childhood nephrotic syndrome in tropical Africa: then and now. Paediatr Int Child Health. 2017;37(4):25968.

3. Odiit A. Common childhood kidney diseases in Uganda and their prevention. Afr Health Sci. 2017;17(4):1126-9.

4. Liu D, Ahmet A, Ward L, Krishnamoorthy P, Mandelcorn ED, Leigh R, et al. A practical guide to the monitoring and management of the complications of systemic corticosteroid therapy. Allergy Asthma Clin Immunol. 2013;9(1):30.

5. Ng JS, Wong W, Law RW, Hui J, Wong EN, Lam DS. Ocular complications of paediatric patients with nephrotic syndrome. Clin Exp Ophthalmol. 2001; 29(4):239-43.
6. Velayudhan KJ, DK C, Menon R, Raveendran JR. A study on ocular findings in children with Nephrotic syndrome. J Evid Based Med Healthc. 2018;5(10): 1022-6.

7. Hayasaka Y, Hayasaka S, Matsukura H. Ocular findings in Japanese children with nephrotic syndrome receiving prolonged corticosteroid therapy. Ophthalmologica. 2006;220(3):181-5.

8. Butcher JM, Austin M, McGalliard J, Bourke RD. Bilateral cataracts and glaucoma induced by long term use of steroid eye drops. BMJ. 1994; 309(6946):43.

9. Kaye LD, Kalenak JW, Price RL, Cunningham R. Ocular implications of longterm prednisone therapy in children. J Pediatr Ophthalmol Strabismus. 1993 30(3):142-4

10. Brito PN, Silva SE, Cotta JS, Falcao-Reis F. Severe ocular hypertension secondary to systemic corticosteroid treatment in a child with nephrotic syndrome. Clin Ophthalmol. 2012;6:1675-9.

11. Agrawal V, Devpura K, Mishra L, Agarwal S. Study on steroid induced ocular findings in children with Nephrotic syndrome. J Clin Diagnostic Res. 2017. 11(3):SC05-SC6.

12. de Vries TW, de Langen-Wouterse JJ, de Jong-Van den Berg L, Duiverman E Hypertrichosis as a side effect of inhaled steroids in children. Pediatr Pulmonol. 2007:42(4):370-3.

13. Jobling Al, Augusteyn RC. What causes steroid cataracts? A review of steroid-induced posterior subcapsular cataracts. Clin Exp Optom. 2002;85(2): $61-75$.

14. Jones R, Rhee DJ. Corticosteroid-induced ocular hypertension and glaucoma: a brief review and update of the literature. Curr Opin Ophthalmol. 2006;17(2):163-7.

15. Razeghinejad MR, Katz LJ. Steroid-induced iatrogenic Glaucoma. Ophthalmic Res. 2012;47(2):66-80.

16. Kyrieleis HA, Löwik MM, Pronk I, Cruysberg HR, Kremer JA, Oyen WJ, et al. Long-term outcome of biopsy-proven, frequently relapsing minimal-change nephrotic syndrome in children. Clin J Am Soc Nephrol. 2009;4(10):1593600.

17. Coondoo A, Phiske M, Verma S, Lahiri K. Side-effects of topical steroids: a long overdue revisit. Indian Dermatol Online J. 2014;5(4):416-25.

18. Sundar G, Young SM, Tara S, Tan AM, Amrith S. Epiblepharon in east Asian patients: the Singapore experience. Ophthalmology. 2010;117(1):184-9.

19. Kawuma M, Mayeku R. A survey of the prevalence of refractive errors among children in primary schools in Kampala district. Afr Health Sci. 2002; 2:69-72.

20. Gheissari A, Attarzadeh $H$, Sharif $H$, Pourhossein M, Merrikhi A. Steroid dependent and independent ocular findings in Iranian children with nephrotic syndrome. Int J Prev Med. 2011;2(4):264-8.

21. Ozaltin F, Heeringa S, Poyraz CE, Bilginer $Y$, Kadayifcilar S, Besbas N, et al Eye involvement in children with primary focal segmental glomerulosclerosis. Pediatr Nephrol. 2008;23(3):421-7.

22. Gaur S, Joseph M, Nityanandam S, Subramanian S, Koshy AS, Vasudevan A, et al. Ocular complications in children with nephrotic syndrome on long term oral steroids. Indian J Pediatr. 2014;81(7):680-3.

23. Olonan LRN, Pangilinan CAG, Yatco MM. Steroid-induced cataract and glaucoma in pediatric patients with nephrotic syndrome. Philipp J Ophthalmol. 2009;34(2):59-62.

24. Urban RC Jr, Cotlier E. Corticosteroid-induced cataracts. Surv Ophthalmol. 1986:31(2):102-10.

25. Kobayashi Y, Akaishi K, Nishio T, Kobayashi Y, Kimura Y. Posterior subcapsular cataract in nephrotic children receiving steroid therapy. Am J Dis Child. 1974;128(5):671-3.

26. Brocklebank J, Harcourt R, SJ M. Corticosteroid-induced cataracts in idiopathic nephrotic syndrome. Arch Dis Child. 1982;57(1):30.

\section{Publisher's Note}

Springer Nature remains neutral with regard to jurisdictional claims in published maps and institutional affiliations. 